\title{
El uso de Internet y las redes sociales en la realidad contemporánea cubana
}

DOI: $10.5935 / 1984-9044.20200024$

\section{Jasely Fernández Garrido ${ }^{1}$ - Universidad de La Habana}

Resumen: En el presente artículo se exponen algunos fundamentos teóricos que abundan sobre las temáticas referentes al desarrollo tecnológico y el impacto social de la tecnología. Internet y las redes sociales online forman parte importante del tema que se propone analizar con una mirada desprejuiciada desde Cuba. ¿Cómo se ha dado el proceso de informatización en la sociedad cubana? ¿Cuáles han sido las políticas seguidas por el Estado cubano? Los beneficios y riesgos que brinda Internet para la Isla son interrogantes que también pretenden ser respondidas en el presente trabajo.

PALABRAS CLAVES: Tecnología, Internet, redes sociales online, Cuba.

\section{The use of the Internet and social networks in the contemporary Cuban reality}

Abstract: This article presents some theoretical foundations that abound on the issues related to technological development and the social impact of technology. Internet and online social networks are an important part of the subject that is proposed to be analyzed with an unprejudiced view from Cuba. How has the computerization process taken place in Cuban society? What have been the policies followed by the Cuban State? The benefits and risks that the Internet provides for the Island are questions that also seek to be answered in this study.

KEY WORDS: Technology, Internet, online social networks, Cuba

\footnotetext{
${ }^{1}$ Doctorante en Ciencias Sociales. Maestra en Ciencias Políticas por el programa de Ciencias Políticas de la Universidad de La Habana. Licenciada en Sociología por la Universidad de La Habana. Docente e Investigadora del Centro de Investigaciones de Política Internacional de Cuba. En estos momentos se desempeña como funcionaria a cargo de los temas académicos, culturales y deportivos en el Consulado General de Cuba en São Paulo, Brasil.
} 


\section{Introducción}

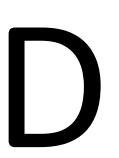

Desde la antigüedad los seres humanos han estado en contacto directo entre sí y con el medio que los rodea.

La necesidad de dar soluciones a las diversas problemáticas que enfrentaban ha sido el motor impulsor para que, de manera paulatina, la humanidad alcanzara el desarrollo científico técnico que tiene actualmente.

Es por ello que temáticas como la tecnología, su impronta en la sociedad y las interrelaciones sociales que se dan mediante redes sociales son abordadas desde diversas disciplinas hace ya más de una década.

Este artículo tiene como propósito ahondar en temas relacionados con la tecnología, las redes sociales, en general, y su impronta en las sociedades contemporáneas. El objeto de estudio está constituido por el análisis de las funciones y alcance de Internet, las redes sociales online, en particular, $y$, como país referente, Cuba. Interrogantes tales como es el uso de Internet en Cuba, qué retos y desafíos representa para el país y cuales han sido las políticas asumidas por el gobierno de la isla son temas abordados.

No se trata de un estudio definitivo, con él solo se pretende acercar al lector a la realidad cubana en las esferas antes mencionadas. Para ello inicialmente se hacen algunas referencias teóricas que facilitan la comprensión del tema a tratar.

relación que este tiene con el desarrollo tecnológico y comunicativo alcanzado en 
la actualidad, porque ello ha revolucionado los modos de interactuar entre los sujetos.

Si bien es cierto que, desde un análisis teórico, el término tecnológico ha sido vinculado a un soporte material, en tanto se ha visto reducido al papel que desempeñan las máquinas y herramientas, que permiten llegar a un fin determinado en cualquier terreno de la producción humana, esta visión única es simple y excluyente, pues deja a un lado el proceso de creación donde interviene la voluntad e ingenio del ser humano para satisfacer las necesidades sociales que cualquier época demanda. De ahí, que al aludir al término tecnológico es imposible desvincularlo a la estrecha relación que tiene con del carácter social de la tecnología y con la cultura de las sociedades con las que interactúa.

Y es que la tecnología encierra en sí misma una doble condición: la posibilidad de ser determinada por la sociedad y al mismo tiempo determinarla. De manera que en ella se evidencian los valores, principios, identidades, perspectivas de quienes la crean, mientras que puede generar en la sociedad valores, principios, identidades, perspectivas y con ello estilos de comportamientos.

De ahí la importancia que autores como Rodríguez (2012, p. 15) le atribuye a recuperar el término tecnología en su sentido social, "Ia cuestión fundamental se desplaza del terreno del "valor» a la reconquista de los "sentidos» de lo tecnológico (...) De lo que se trata entonces es de devolverle a la tecnología la fuerte carga asociada a los sentidos, a la apropiación que los ciudadanos hacen de ella, más allá de lo cuantificable o medible en términos económicos."

Pues desde su naturaleza instrumental y simbólica la tecnología te permite mirar las relaciones entre los sujetos y su entorno, se conforma de esta manera significados asociados a los usos y prácticas de los instrumentos tecnológicos, lo cual genera una relación recíproca entre sujeto y objeto. Por esta razón es posible afirmar que la tecnología remite a nuevos modos de percepción, 
nuevos usos del lenguaje y de nuevas escrituras.

Ello explica los profundos cambios en los procesos comunicativos y de consumo en el contexto actual, donde las audiencias, tradicionalmente consumidoras de información, se convierten en usuarios activos que producen información y con ella se recontextualiza todo el aparato simbólico de interpretaciones de los sujetos.

Para que esto ocurriera fue preciso la llegada de Internet, la web 2.0 y la existencia de los SRS o Sistemas de Redes Sociales. Es que es precisamente el ciberespacio el lugar que transforma las relaciones entre emisor y receptor. En él se rompen las barreras espacio tiempo o tiempo de ocio y de trabajo. Los flujos de información bidireccionales se convierten en multidireccionales en dependencia de la capacidad del usuario para realizar diferentes actividades simultáneamente. Otra de las nuevas características del escenario comunicativo actual es la capacidad de selección y jerarquización de contenidos que tiene el usuario.
A partir de eso se hacen cada vez más pequeñas las distancias entre los medios de comunicación masiva tradicionales y sus públicos, pues estos, convertidos en usuarios a través de la participación activa asumida, logran derribar, en cierto modo, los llamados muros del silencio, que no son más que las barreras que hacen invisibles las problemáticas que no benefician a los intereses de la clase dominante.

El uso de las TIC provoca que los individuos se emancipen y desarrollen capacidades técnico-comunicacionales, cognitivas y valorativas a partir de su relación constante con otros usuarios de la red. También dota al usuario de mayor poder, si no para tomar las decisiones, por lo menos para hacer sentir su voz

Sobre el tema plantea Rodríguez (2012, p. 30), las TIC han maximizado las posibilidades del sujeto social de apropiarse de herramientas de lucha $y$ posicionamiento político en el espacio técnico, les ha dotado el andamiaje necesario para convertirlos en artesanos de productos simbólicos". "La irrupción de las TIC, y especialmente de Internet y 
de la Web 2.0, en la vida de los seres han habilitado otro escenario de luchas e ideologías políticas y de construcción de la opinión pública.

A partir de la diversidad de los universos culturales que confluyen en el espacio online se particularizan los modos de actuación de los sujetos, al mismo tiempo en que surge una cultura común que da lugar a prácticas comunicativas que responden a una nueva cultura del decir y el hacer. Ocurre de esta manera un fenómeno comunicacional donde las mediaciones culturales inciden en los procesos de percepción y apropiación de los públicos.

Para Orozco (1993, p. 61) las mediaciones son "un proceso estructurante que configura y reconfigura, tanto la interacción de los auditorios con los medios, como la creación por el auditorio del sentido de esa interacción".

El autor las clasificas en 4 tipos diferentes. Estos son: aquellas que depende de la cultura que poseen los individuos y sus características propias, lo que incluye los aspectos cognitivos y valorativos que tenga, así como su edad, sexo, nacionalidad. A estas mediaciones las Ilamó individuales. Las mediaciones situacionales están vinculadas al momento de recepción y las características del entorno. Por su parte las mediaciones institucionales expresan las relaciones existentes entre sujetos e instituciones sociales. Por último, y no menos importantes, se encuentran las que el autor definió como mediaciones tecnológicas que emanan de los medios como institución y como dispositivos.

Las mediaciones explican, de cierto modo, los diferentes usos que hacen los sujetos de la tecnología para formar parte de la comunidad de internautas. De ahí, que desde la imbricación de diferentes elementos se da paso a la construcción de un yo y luego de un nosotros. Como es natural esto origina una opinión pública

La opinión pública se da a partir de un conjunto de interacciones entre individuos, de disenso y consenso sobre temas de interés común. De ella se forman las opiniones de los sujetos al mismo tiempo que son los sujetos 
quienes la forman. La opinión pública, al igual que la cultura, tiene también un fuerte componente axiológico porque de ella devienen acciones y fuerzas colectivas que inciden en la vida política de cualquier país.

Por esta razón se concuerda con Carmenati (2012, p. 50) cuando dice que "Ia opinión pública tiene un rol legítimo en la vida política". Aunque, claro, no se puede olvidar lo planteado por Rodríguez (2012, p. 45) cuando alude a que "Ia opinión pública constituye un poder comunicativo que no suplanta al administrativo, sino que puede incidir sobre él, al otorgarle o restarle legitimación".

La interactividad y la horizontalidad comunicacional que se dan en el espacio online constituye un estimulante para el debate, para la búsqueda de información política y también para la creación y proyección de contenidos políticos. Por lo que es posible afirmar que el ciberespacio aumenta las posibilidades de participación política a través de una diversidad de posibilidades entre las que se encuentran los debates públicos.

\section{Los Sistemas de Redes Sociales online en el mundo contemporáneo}

Claro, que las redes sociales existen desde que el ser humano necesitó de la colaboración mutua para lograr un objetivo común. Son varias las ciencias sociales que han estudiado este fenómeno, pues está presente en cada una de las interacciones que caracterizan la dinámica social de todos los tiempos.
Los estudios referidos a las redes sociales se basan fundamentalmente en las interacciones que se dan entre los sujetos y de ahí los grupos que estos constituyen. Sobre estas plantea De Rivera (2011, p. 10) "Ias redes sociales refieren las estructuras básicas de 
relaciones de toda sociedad, por medio de las que se desarrolla la subjetividad".

Sin embargo es, una vez más, Internet y la llegada de web 2.0 las que hacen que este fenómeno longevo se revolucione a través de los Sistemas de Redes Sociales, SRS, ya antes mencionados, y con él también lo hagan las maneras de comunicación y de interacción social.

En el espacio online las redes sociales comienzan a partir de las relaciones que los sujetos establecen de manera cotidiana en su espacio offline, sin embargo, una vez dentro de ellas el propio proceso de socialización online dinamiza la interrelación con los otros usuarios de la red y se conforman entonces vínculos interpersonales e intergrupales, donde, las expresiones se dan mediante la unidad entre los rasgos técnicos y culturales que brindan las plataformas de comunicación hipermedia empleadas por los usuarios que se encuentran en el ciberespacio.

El elemento primario para que esto ocurra es la interfaz, la cual es definida por Marrero (2013, p. 67) como "el lugar y el "contexto mediador donde se hace posible la interacción de los sujetos con los dispositivos tecnológicos".

Las redes sociales online cuentan con interfaces atractivas y con altos niveles de usabilidad, lo cual facilita su uso para usuarios de cualquier edad, género o país. Y es a partir de esta interfaz donde se crean páginas personalizadas que contienen textos, imágenes, audios, videos, datos personales. En ellas los usuarios de la red existen y construyen su identidad, su imagen. También desarrollan maneras de socialización adaptadas al nuevo escenario, el cual permite hacer públicas las relaciones personales y sus tipos. Esto, unido a la dinámica conexión, posibilita la colaboración, el intercambio, caracterizados por el modelo de vida mediático que amplía el sentido de identidad, dando lugar a un nosotros que se traduce en imágenes colectivas.

Este proceso comunicativo va más allá del esquema cotidiano de emisor y receptor porque implementa un modelo de comunicación multidireccional en el que emisores y receptores intercambian sus roles. Ese modelo comprende desde 
el mensaje hasta las acciones comunicativas que dan lugar a la atribución de significados. En este sentido, la comunicación es un proceso continuo de intercambio que determina la construcción de significados compartidos.

Las interacciones entre los diferentes usuarios de la red poseedores de culturas y valores, marcados por el momento histórico en el que viven $y$ sus experiencias individuales y colectivas, dan lugar no solo a la construcción de significados sino también a la creación de una cultura. A partir de la combinación de sus prácticas culturales discretas y separadas se generan nuevas percepciones, valores, objetivos y prácticas, lo cual da lugar a la existencia de culturas híbridas. Sobre esto García Canclini apuntó la importancia de reconocer que, en la objetividad del proceso, la participación del individuo es natural si se es parte de un mundo interconectado.

Los espacios de socialización que brindan las redes sociales no solo dotan a los sujetos de una cultura híbrida, si no también pueden considerarse espacios para un debate público más participativo.

En los marcos de esta investigación se coincide con el criterio emitido por Rodríguez (2012, p. 30) cuando plantea que las plataformas de redes sociales, al estimular la producción infocomunicativa constante y la interacción entre individuos, instituciones $\mathrm{y}$ comunidades, promueven el ejercicio ciudadano, pues se instituyen en lugar de encuentro y de reconocimiento, al tiempo que encauzan procesos de socialización. Sin embargo, los SRS no son garantes de la democracia ni fomentan per se formas de organización; ellos devienen "instrumentos, herramientas, medios ubicuos reutilizados por la ciudadanía para convocar, involucrar, participar en el debate, difundir información, diluir los actores individuales en sujetos colectivos y recuperar el espacio público.

Esto explica el incremento de prácticas ciudadanas articuladas en las redes sociales con el objetivo de manifestarse en cuanto a temas que trascienden los intereses nacionales y que se convierten 
en interés internacional. La participación es un elemento importante a tener en cuenta, aunque todos no participan de igual manera, ni en todos los procesos, pues en ello interviene la decisión de cada sujeto.

Autores como Morell \& Subirats (2012) destacan elementos significativos que caracterizan la participación en las redes sociales, estos son: se está en presencia de un sistema abierto a la participación, donde la participación asume diversas formas y grados, que de alguna manera se integran. Esta es descentralizada, asincrónica y pública; es autónoma, por lo que es el sujeto quien decide el nivel de compromiso que quiere asumir y de qué maneras quiere contribuir; es voluntaria y activa: La participación no sólo es deliberación sino también acción, implementación. Esta participación social puede realizarse desde su particularidad, la participación política. La participación política que se desarrolla en las redes sociales online está mediada por los elementos de la cultura política que caracterizan a los sujetos. Su reconocimiento no siempre es consciente, pues la participación política tiende a ser vista por los sujetos como una participación social.

Aunque claro, no siempre es así, pues la búsqueda de contenidos políticos, la construcción y proyección en las redes sociales de este tipo de contenidos, dan lugar a una participación política consciente. Al decir de Colombo (2012, p. 751) "Ias características de interactividad y horizontalidad del entorno online, podrían aumentar el deseo de más formas directas de participación política". Para Chaguaceda (2008, p. 37) "a partir de la participación, el ciudadano se erige no solo como sujeto de derechos, sino también actor generador y regenerador de la convivencia social y sus condicionantes, en un proceso que se reproduce $y$ expande tanto en la institucionalidad estatal como en los espacios de la Ilamada Sociedad Civil."

La búsqueda de información política y la participación que se establece a partir de los conocimientos políticos adquiridos, dota a los sujetos de la capacidad de convertirse en actores estratégicos 
legitimadores o no de los sistemas políticos.

La visibilidad mundial que distinguen las maneras de participación política que se asumen en el espacio online no solo genera opinión pública nacional, sino internacionaliza la opinión pública que se tiene de un proceso político, de un país, de un líder político o de las relaciones bilaterales y multilaterales que se dan entre los países.

Este hecho genera, de manera inevitable, una imagen país que, construida desde la participación de los sujetos en sus redes sociales, gana en valor; precisamente, por ser los sujetos quienes, desde su rol de usuarios de la red, construyen y proyectan la imagen a partir de la voluntad de lograr una participación política. Se erigen así, las redes sociales como espacios de socialización política y como medios alternativos que democratizan las imágenes de los países, que son impuestas por el orden hegemónico mundial, debido al poder que tienen sobre los grandes monopolios de las comunicaciones.
Aun así, es solo una alternativa en cuanto a que la brecha digital es grande. Las diferencias económicas entre los países y los ciudadanos hacen que todos no se puedan conectar a la red de redes, ni todos tengan incorporados los conocimientos y habilidades necesarias para el trabajo. Sobre el tema Díaz \& Sokooh (2013, p. 62) exponen "La brecha actual entre inforricos e infopobres desborda el dominio de herramientas digitales; e incluye la necesidad de desarrollar competencias tecnocomunicativas emancipadoras con el fin de transformar grandes volúmenes de datos en decisiones informadas $y$ argumentadas que promuevan la calidad de la participación ciudadana en la vida pública de la nación. Aquellos que carecen de dichas competencias, aun con acceso a la Red, sufren una nueva suerte de exclusión social de tipo cognitivo porque les resulta imposible decodificar, reinterpretar y aprovechar esos datos para (auto)incluirse en los procesos políticos, dominados en lo fundamental por actores institucionales y gubernamentales". 
Desde esta perspectiva, Internet y las redes sociales pudieran tener un efecto aislador. Sin embargo, no se trata solo de ver las limitaciones, sino de conocerlas y transformarlas. Entre las variantes para lograrlo están: la informatización de la sociedad, lo cual disminuye la brecha digital y la educación digital a los sujetos que lo necesiten. También se considera necesario el conocimiento de tipologías de redes que existen, las particularidades comunicativas que cada una de ellas tiene, así como el lugar que ocupan en las preferencias de los usuarios.

Es preciso tener en cuenta que, en dependencia de sus características, los usuarios prefieren más una red que otra; también es común la presencia de un mismo usuario en diferentes redes sociales.

En Cuba una de las redes sociales más aceptadas por la población es Facebook. Como es conocido esta red social surge en el 2004 y su creador, Mark Zuckerberg, tenía como propósito conectar a la población de la Universidad

\footnotetext{
2 La información personal que se pide es un correo electrónico, el nombre, el sexo, fecha de
}

de Harvard. Su popularidad hizo que evolucionara con rapidez y ya para el 2006 no solo serían parte de ella los estudiantes de otras universidades, sino también toda aquella persona que contara con un correo electrónico.

Su surgimiento fue un paso importante en las maneras de interacción social a nivel mundial. La creación de blogs, la subida o etiquetados de fotos, videos; la mensajería, el correo, los enlaces e hipervínculos, son elementos que componen Facebook y que potencian su aceptación entre los internautas, pues en ella confluyen las herramientas más usadas por los usuarios de Internet. Pudiera decirse que esto explica la popularidad internacional que mantiene en la contemporaneidad a pesar de coexistir con otras redes sociales.

En ella se recopilan extensas cantidades de datos de los usuarios lo que se hace mediante las diferentes opciones que brinda; entre estas se pueden citar: la información solicitada al crear los perfiles en Facebook ${ }^{2}$, los datos que se generan a musicales, de películas, los hábitos del lecturas, estado civil, qué grupos "me gustan" dentro de 
partir de la participación desplegada en la red con los botones de "me gusta", "me encanta", "los emoticones" o cuando se comparten o se publican contenidos. Otras de las maneras que permiten obtener información es mediante los comentarios que se hacen con relación a un tema determinado, así como la interrelación que el usuario hace con videos, promociones o anuncios de ventas de productos. Esta es una forma de registrar datos e inclinaciones de consumo de las personas, lo que también aporta información sobre su personalidad. El uso de las etiquetas es otro de los elementos importantes que indican información y dan lugar a la participación.

El diseño de la arquitectura de Facebook, así como su política de uso y la esencia de la red, incitan a la participación abierta y la creación de perfiles no anónimos, ya sean personales o grupales; claro está, siempre hay personas que prefieren el anonimato y trabajar con sobrenombres o seudónimos.
Sobre esta red Sued (2010, p. 59) expresó “En Facebook el usuario nunca está solo, no existe uno sin el otro. Las identidades son construidas colectivamente o en la suma de las interacciones con otros", "la mirada del otro está presente en diferentes posibilidades de la arquitectura: comentarios, tags, pulgares hacia arriba, «me gusta». El comentario es el lugar de la mirada y la opinión". El autor alude a la participación que brinda la red social, al respecto indica Sued (2010, p. 70) "para participar en dicha red social solamente es necesario estar en Facebook, formar parte de él".

Y es que esta red social se caracteriza por aumentar el campo participativo a través de la producción y consumo de contenidos. Facebook brinda a sus usuarios la posibilidad de construir y proyectar contenidos a partir de la creación de los perfiles personalizados. EI lugar donde esto ocurre es el muro, en él se suben álbumes de diferentes eventos de la vida cotidiana, estados de ánimo, 
música $u$ otras imágenes que resulten significativas.

El dinamismo de Facebook lo convierte en un poderoso medio de difusión de contenidos e información lo cual facilita la creación de identidades en la web y la legitimación de estas a partir de la interacción entre los usuarios. La existencia de los perfiles da lugar a identidades que proyectan imágenes que se internacionalizan y traspasan lo individual para adquirir carácter grupal, nacional e internacional.

Este hecho en sí constituye uno de los recursos útiles que ofrece Facebook, unido a la posibilidad que ofrece de conocer personas de diferentes partes del mundo y de ser un facilitador de la concientización y movilización de la ciudadanía.

Sin embargo, el hecho de que Facebook sea la plataforma con mayor acceso a gran cantidad de datos personales, según Tello (2013, p. 41) "más de cincuenta y siete patrones de datos personales pueden ser obtenidos por dicha red social", trae consigo complejidades que se traducen en riesgo cívico por las insuficientes políticas de seguridad para la protección de la identidad y la privacidad, pues incluso aunque los usuarios prefieren reservar algunos aspectos de su vida cotidiana, estos pueden ser revelados por sus contactos a partir de la información que brindan.

Lo descrito con anterioridad explica el uso de Facebook por grandes compañías comerciales, políticos y países para adquirir información de los sujetos y luego crear campañas comunicacionales que logren captar su atención y generar opinión pública y modos de actuación.

Este elemento, aunque significativo y trascendente, no implica que sea preciso o conveniente dejar de ser parte de Facebook, solo enfatiza la importancia de: estar presente en el espacio online que brinda la red y la necesidad de realizar estudios que, desde la mirada multidisciplinaria, expliquen su funcionamiento, uso, los contenidos que se mueven en la red y sus niveles de aceptación para, a partir de ahí, trazar estrategias comunicacionales en función de los intereses nacionales. 
En el caso particular de Cuba, como anteriormente se dijo, Facebook es una de las redes sociales de mayor preferencia en la población en general y, particularmente, en los jóvenes. Un acercamiento al estudio de cómo es usada esta red en Cuba es necesario, sin embargo resulta imposible sin antes conocer el uso de Internet en la Isla.

\section{Cuba y el acceso a Internet}

Son varios los criterios que circulan en la red de redes y apuntan a que en Cuba las personas no tienen acceso a Internet por decisión del gobierno cubano. Algunos de estos criterios elementos plantean que esta decisión se basa en la protección a la población por los malos contenidos que circulan y su incapacidad para detectarlos; otros aluden a la necesidad del Gobierno Cubano de mantener al pueblo dentro de una burbuja que la aísle para que esta no conozca la realidad del mundo y el engaño en el que viven.

Ambos criterios, desde diferentes variantes, coinciden con el objetivo de construir y proyectar una mala imagen de Cuba, del proceso revolucionario, y evidenciar una ruptura y desconfianza entre la alta dirección del país y las masas.

Sin embargo, los hechos demuestran que han sido muchos los esfuerzos y recursos invertidos por el Estado cubano para desarrollar la infraestructura necesaria y garantizar el acceso del pueblo a navegar por Internet. Por otro lado, a pesar de la voluntad política existente ha sido un proceso complejo que ha transitado por diferentes etapas y cada una de ellas ha estado marcada por el carácter de las relaciones entre Cuba y Estados Unidos y el intenso bloqueo económico, comercial y financiero impuesto a la Isla durante casi 6 décadas.

De ahí que, a pesar de que la isla está rodeada por cables de fibra óptica, controlados por Estados Unidos, no es 
hasta 1996 que Cuba logra conectarse a la red de redes mediante un enlace satelital, por lo cual debía pagar un mayor precio por una pequeña capacidad de conexión. Otras de las limitaciones del bloqueo es que obstaculiza de manera directa la adquisición de tecnología. Para adquirirla es necesario recurrir a mercados distantes y pagar riesgos comerciales de manera que se encarecen los productos, se frena el desarrollo tecnológico $y$, por consiguiente, las posibilidades de acceso a Internet.

Sobre Internet y su utilidad, así como la necesidad de informatizar el país y su población, fueron numerosas las reflexiones emitidas por Fidel Castro, líder de la Revolución Cubana, quien desde 1997 dejó claro que una computadora conectada a la red de Internet era una posibilidad de hacer llegar un mensaje, un pensamiento a millones de personas en el mundo. Sobre el cambio en los modos de comunicación y la democracia en la red, Fidel advirtió, añadiendo importancia a este revolucionario fenómeno contemporáneo, que las grandes cadenas de comunicación disminuirían su influencia monopólica pues la posibilidad que brinda Internet de transmitir mensajes de disimiles remitentes es enorme. Sin embargo, para él una limitación y preocupación latente era la desigualdad que este fenómeno generaba entre las poblaciones del mundo, pues mientras que en América Latina en 1999 tenía acceso a Internet el $2 \%$ de la población, en países como EE.UU. más del $70 \%$ de su población estaba conectada. Esto es lo que hoy se conoce como la brecha digital entre inforicos e infopobres.

Esto explica el interés profundo que dio a Internet para a la labor de los periodistas, los científicos, los médicos y los profesionales cubanos en general, así como la esfera de la cultura. Puso de manifestó que entendía claramente que quien tuviera una computadora conectada dispondría de todos los conocimientos publicados y eran precisamente estos conocimientos unidos a los principios éticos quienes hacían nacer las ideas. Por tales razones urgía conectar a Cuba, unirse al escenario de las redes globales de información y todos los medios modernos de 
transmisión de información e imágenes. En una entrevista publicada en 2011 en el periódico oficial Granma afirmó que "Internet ha puesto en nuestras manos la posibilidad de comunicarnos con el mundo" (...) "En un mundo donde los medios de comunicación estaban controlados por minorías, Internet parecía estar inventada para nosotros los cubanos" ${ }^{3}$.

Sin embargo, hacer esto realidad habría de ser un proceso largo que requirió de constancia y un trabajo minucioso y costoso, lo cual reflejó la profunda voluntad política del Estado cubano. Gracias un acuerdo con Venezuela, no es hasta el 2013 que comienza a funcionar el cable de fibra óptica ALBA 1 de 118 puntos de navegación, lo que permitió un avance en la informatización del país. Si bien, en una primera fase, la política fue garantizar el acceso a la conexión a personas jurídicas e instituciones fundamentales para el desarrollo de Cuba, como las universidades, los centros de investigación, las instituciones de salud, los medios de comunicación masiva, artistas e intelectuales. Fue a partir del 2015 que, como política del país, se procedió a la ampliación de los servicios y se crearon espacios públicos donde, a partir de la instalación e implementación de tecnología Wi-Fi, todo ciudadano que tuviera una cuenta cubana denominada Nauta ya puede conectarse utilizando sus teléfonos móviles, ordenadores y tabletas. También existen otras alternativas como la conexión en las salas de navegación de los hoteles o los Ilamados Jóven Club de computación, que existían antes de que se instalaran las zonas Wi-Fi.

En la actualidad, es posible hablar de un salto cualitativo y cuantitativo favorable en cuanto al acceso que la población cubana tiene a las comunicaciones, en general, y en particular, a Internet, lo cual ha sido posible por el desarrollo de la infraestructura alcanzado. Esto se manifiesta en los siguientes datos emitidos por el Ministerio de Comunicaciones de Cuba: Las telecomunicaciones cuentan con la instalación de más de 62000 servicios en

\footnotetext{
${ }^{3}$ Castro, F. (2011) Entrevista publicada en el periódico cubano Granma
} 
telefonía básica, con lo que se llegó a más de 1300194 líneas fijas en el país. En cuanto a la telefonía pública se instalaron 633 nuevos servicios, que elevan el total instalado en el país a casi 61 000; también se alcanzaron más de seis millones suscriptores de telefonía celular, lo que implicaba un crecimiento de casi 650000 usuarios. Más del 35\% de las 3364 radiobases en funcionamiento se instalaron en el 2019. Se incrementó al $85 \%$ la cobertura poblacional de la señal de telefonía celular y la telefonía móvil 4G está presente en todas las capitales provinciales y municipios de la capital, alcanzándose un $22 \%$ en la cobertura poblacional. Todo esto contribuye a que más de 6.5 millones de cubanos acceden a Internet por diferentes vías.

Si bien se contaba con más de 3.4 millones de usuarios del servicio de Internet a través de datos móviles y de ellos, más de 650000 en 4G, para el 2019 las áreas colectivas de acceso a Internet crecieron en 229 llegando a más de 1500 áreas WIFI y a más de 650 salas de navegación. La conectividad internacional del país incrementó un 30\% su capacidad durante el 2019.

Otro aspecto cardinal en el proceso de informatización es la conectividad de las instituciones, la que creció un $13.5 \%$, alcanzando a más de 48600 en todo el país, gracias a lo cual sectores como la educación, la salud y el turismo ampliaron su conectividad. Hoy en día las universidades cubanas están conectadas por fibra óptica con incrementos significativos en su ancho de banda, 288 instalaciones de los Joven Club están también conectadas por fibra óptica, y se comenzó la instalación de la red inalámbrica, llegando a 70 instalaciones y 15 sitios altos mayoritariamente en la Habana. De igual manera se amplió la conectividad en las oficinas provinciales de entidades como la $\mathrm{ONEI}^{4}, \mathrm{MFP}^{5}$,

\footnotetext{
${ }^{5}$ El Ministerio de Finanzas y Precios (MFP) es el organismo de la Administración Central del Estado de Cuba que tiene la misión de proponer al Estado y al Gobierno las políticas financiera, presupuestaria, tributaria, contable, de tesorería, de patrimonio, de precios y de crédito público, así como las relacionadas con el seguro y, una vez aprobadas,
} 
ONAT $^{6}$, lo que está facilitando la actividad de trámites y servicios.

El programa de informatización de la sociedad cubana ha priorizado, asimismo, lineamientos políticos claros enfocados al desarrollo del gobierno y el comercio electrónico. El primero trata de asegurar una vía rápida de comunicación entre el pueblo y el gobierno cubano. Mediante el uso de plataformas online y las propias redes sociales, cualquier ciudadano puede plantear sus opiniones a las entidades responsables y sus directivos, mientras el segundo busca la viabilidad de los procesos comerciales, la rapidez y la eficiencia. Ahora bien, la ampliación de la conectividad y el acceso a la tecnología necesaria no son los únicos problemas que Cuba enfrenta ante Internet.

\section{Internet y los problemas que enfrenta la sociedad cubana}

Aunque el uso de Internet es imprescindible y el Estado Cubano tiene como una de sus políticas priorizadas la informatización del país, no es menos cierto que también trae consigo riesgos de los cuales Cuba no escapa. El ciberterrorismo, los cibercrímenes, el ciberespionaje, son algunos de los temas frecuentes a enfrentar en el espacio

dirigir y controlar su cumplimiento para mejorar la gestión y calidad de los servicios públicos ${ }^{6}$ Oficina Nacional de Administración Tributaria (ONAT) es una institución pública encargada de la online y las maneras de manifestarse son diversas.

Entre ellas es posible citar el uso de softwares maliciosos. Se le denomina así a la implementación de diferentes tipos de programas informáticos destinados a perturbar al usuario y a su equipo. Entre los ejemplos más comunes se encuentran los virus que pueden alterar desde el uso

gestión de la recaudación, cobranza y fiscalización de los Tributos. 
de las máquinas hasta causar la pérdida de la información. En el caso particular del spyware, el dispositivo del usuario queda sometido a vigilancia por parte del atacante. Otra variedad de software malicioso son los ransomware, cuya implementación ha aumentado en los últimos años y se caracterizan por ocasionar una restricción severa en el acceso a las distintas partes y funciones del mismo sistema. Generalmente, este tipo de ciberdelitos van acompañados de extorsión, pues los atacantes piden rescate a cambio de liberar el sistema.

La suplantación de identidad, es otro de los crímenes que están presentes en el escenario actual, este consiste en el robo de los datos personales de un usuario para darle un fin ilícito y puede ser usado por diferentes causas y de diversas maneras, como mediante la apropiación ilegal de la contraseña de un correo electrónico, de una red social, datos de tarjetas bancarias. Sus consecuencias pueden ir desde la difusión de una información falsa, el bullyng hasta el fraude bancario. Estos últimos también se vinculan mucho con la existencia de sitios web falsos.
$Y$ es que en la contemporaneidad se vive en un mundo hiperconectado, donde los datos informáticos, así como las bases de datos son activos sociales de primer orden para el nuevo contexto social online en que se desenvuelven la vida cotidiana de los individuos.

De ahí, que la educación a la población es sumamente importante. Por ello, un fenómeno priorizado para Cuba es la cibereducación. Para llevarla a cabo, el país realiza un número de programas educativos en las escuelas, en los centros de trabajo y en la televisión que ilustran los riesgos existentes. El objetivo de estos es lograr una población preparada para defenderse y defender al país de los delitos online.

Los delitos online hacen que las sociedades del mundo se planteen como enfrentar una nueva modalidad de delitos caracterizados por su virtualidad. Cuba también prepara su sistema jurídico para ello. En cuanto a este tema, Maya (2013, pp. 682-683) introduce ideas con las que concordamos y cito: "se intuye ya la necesidad y la importancia de proteger la seguridad de la información como un bien jurídico de naturaleza 
intermedia, que a su turno permita tutelar otros derechos constitucionales y bienes jurídicos como el patrimonio económico, la intimidad personal y la autodeterminación informática."

Si bien estos delitos pueden afectar al mundo entero existen otros que van dirigidos directamente hacia Cuba. Estos siguen una marcada línea de acción organizada desde EE.UU. y tienen como objetivo fundamental eliminar a la Revolución Cubana. Por ello un elemento clave al cual han apostado es a la construcción y proyección de una imagen país que evidencie la ruptura entre la máxima dirección del Estado cubano y las masas populares, así como promover un cuadro de decadencia y la desesperanza del pueblo por políticas supuestamente desacertadas que toma la máxima dirección del país.

En este sentido el uso de las redes sociales por parte de estos enemigos de Cuba ha sido fundamental y tiene una doble función: por una parte, internacionalizar la imagen Cuba construida por EE.UU. y crear una mala opinión pública que justifica la existencia de su genocida política del bloqueo financiero, económico y comercial impuesto a la Isla por casi 60 años. Otro modus operandi descansa en el establecimiento de contactos directos con la población cubana para al apoyarse en las necesidades del pueblo, ejercer influencia, de manera directa, en campañas comunicacionales, donde los individuos actúen en la dirección señalada por sus organizadores, creyendo que siguen sus propias razones.

Si una vez usaron la construcción de líderes de opinión como Yoanis Sánchez y su blog Generación $\mathrm{Y}$, o los llamados periodistas independientes, unidos a pequeños grupos como las Damas de Blanco, hoy apuestan por una nueva figura que nace en las redes sociales, Los influencers. Su presencia en el mundo online es tan fuerte que, mediante habilidades comunicativas desarrolladas, son capaces generar cambios de pensamientos, actitudes y dar lugar a nuevas tendencias. Esto es posible por la gran credibilidad que estas personas logran inspirar en sus seguidores; de ahí, que son diversos los temas en los que se especializan. Continúa con el marcado interés de empoderar a sectores de 
cubanos como voces antisistema. Esta política indudablemente, coadyuva a la guerra mediática existente de la cual forman parte las fake news, los constantes descréditos a la profesionalidad de los médicos cubanos o la proyección de imágenes de grandes colas que muestran el desabastecimiento en la Isla, así como la omisión de logros en el protocolo implementado por Cuba para controlar la actual pandemia que azota al mundo, la COVID-19, por citar algunos ejemplos. Sobre este último tema vale señalar el bloqueo reciente de cuentas cubanas oficiales en el canal de YouTube y redes sociales como twitter y Facebook provenientes del periódico Granma y el programa televisivo La Mesa Redonda. El propósito fue impedir que el mundo conociera sobre la existencia de la vacuna cubana contra la COVID-19, cuyo nombre es Soberana 01, lo que es una muestra del alto desarrollo de las ciencias en Cuba puestas al servicio de la humanidad.

Aunque con los mismos objetivos, la guerra mediática ha mutado con el desarrollo de nuevas tecnologías tácticas y estrategias. Uno de sus nuevos rasgos es el cambio, la trasferencia, de lo informativo a lo emocional. La información ahora, en buena medida, es utilizada para activar resortes de molestia que se deriven en desconfianza hacia todo lo que provenga de ciertas directivas políticas indeseadas por los centros de poder hegemónico. En el caso de Cuba, persigue fomentar la desconfianza hacia la dirección política del país.

Estas nuevas corrientes han dado lugar a un aumento considerable de páginas webs pertenecientes a influencers cubanos, casi en su totalidad establecidos en Estados Unidos, que se autoproclaman como disidentes o libertadores y luchadores contra el régimen comunista. Su presencia en redes sociales, tan populares como Facebook, es también mayor. Los contenidos que publican, combinan imágenes y titulares con problemáticas actuales de interés para los cubanos. Los textos son una simple mezcla de mentiras con verdades o sin verdades. Siempre registrando hechos aislados intrascendentes, que no constituyen tendencias, mientras en Estados Unidos y 
otros países capitalistas si representan problemas, como el racismo, los atropellos policiales, los feminicidios, etc... Lo importante es el impacto emocional que da el mensaje emitido por la combinación entre imagen y titular el cual permite incluso, sin ser abierto, posicionar el tema. Con ello se busca re direccionar cada debate que se desarrolla en las redes sociales para que, lejos de ser una crítica constructiva, el espacio online se convierta en un lugar de expresión antigubernamental.

Ahora, más que nunca, se evidencia y se reconoce, de forma desembozada e impune el financiamiento que EE.UU. le dedica a su política de comunicación contra Cuba, donde Internet y las redes sociales constituyen espacios de penetración gradual y constante, que se proponen generar efectos subjetivos en los individuos. El objetivo fundamental es, al decir de (Gómez 2020) "construir una especie de "farándula virtual» en la que, a mercenarios al servicio de la estrategia de Estados Unidos contra

${ }^{7}$ Gómez Sánchez Javier (2020) “Guerra Mediática: de la racionalidad a la motividad" https://www.cubainformacion.tv/opinion/20200730
Cuba, los veamos como nuestros "amigos de Facebook», cual si se tratara de la actividad social más natural del mundo"'?

Sin embargo, para lograr esto fue necesario crear todo un proyecto el cual fue expuesto por Wikileaks en un cable de quien fuera en el 2009 jefe de la entonces Sección de Intereses de Estados Unidos en Cuba, en el que expresa la imposibilidad de que el grupo de "disidentes" cubanos pudiera derrotar al gobierno. También se hacía alusión a que como los artistas e intelectuales, blogueros no pertenecían a ninguna organización "disidente" entonces los Estados Unidos.

Sin embargo, para lograr esto fue necesario crear todo un proyecto el cual fue expuesto por Wikileaks en un cable de quien fuera en el 2009 jefe de la entonces Sección de Intereses de Estados Unidos en Cuba, en el que expresa la imposibilidad de que el grupo de "disidentes" cubanos pudiera derrotar al gobierno. También se hacía alusión a a-la-emotividad fecha de consultado 30 de julio de 2020. 
que, como los artistas e intelectuales, blogueros no pertenecían a ninguna organización "disidente" entonces los Estados Unidos.

Según Sánchez, por esta razón, tendrían que (2020) "Sacar a alguien de Cuba, prepararlo, asignarle un financiamiento no proveniente directamente del gobierno de EEUU, declarar transparencia en el origen y uso del dinero y proclamar preocupación por asuntos ciudadanos como el derecho a la información y los problemas de la comunidad insuficientemente atendidos por instituciones gubernamentales, organizaciones de masas y la prensa cubana. Este era el procedimiento, pero se necesitaban nombres sin pasado

\section{Jóvenes \& Internet}

La juventud es un sector poblacional que con facilidad convive en el espacio de socialización online, que brindan las redes sociales de internet, por lo que su presencia en él es cada vez mayor. Los contrarrevolucionario $y$, si estaban conectados con la academia, los medios de comunicación y la naciente comunidad de blogueros cubanos, mejor."

Esto es justo lo que se puede apreciar en la actualidad, donde el objetivo fundamental es la conexión efectiva con la sociedad cubana mediante el uso de mensaje mediante las redes sociales.

Aunque son diversas las edades de las personas que confluyen en el espacio online, son los jóvenes quienes más experiencia tienen en este tipo de participación social, que se da en las redes sociales, por lo que a ellos EE.UU. les ha dedicado un espacio importante en su política.

modos de estar y participar son disímiles y muestran desde diferentes realidades sus vidas cotidianas, sus gustos $y$ aspiraciones. 
Entre las publicaciones más frecuentes se pueden apreciar las fotos con las familias, los amigos, las actividades en los centros de trabajo y, en el caso particular de los jóvenes universitarios, las actividades que realizan en la universidad, forman parte importante de su universo online. Aunque la publicación de contenidos, mayoritariamente, se caracteriza por imágenes de momentos felices, también es posible observar cómo, de manera consciente, asumen una participación donde las críticas sociales reflejan valores importantes de la cultura política cubana, como la solidaridad, el patriotismo, la lucha contra de las injusticias sociales y la defensa de soberanía cubana.

El objetivo de influir sobre los jóvenes es el que mayor interés han tenido para la política de EE.UU. hacia Cuba en cada una de sus administraciones desde el triunfo de la Revolución Cubana. Por lo que hacia ese sector poblacional se ha dirigido un importante número de sus políticas subversivas, dirigidas, fundamentalmente, a manipular a los jóvenes universitarios.
Un ejemplo es el anuncio realizado por EE.UU. el 24 de diciembre de 2014, a solo uno semana del restablecimiento de las relaciones diplomáticas entre ambos países. En él se convocaba a organizaciones estadounidenses, o extranjeras, interesadas en programas que promovieran los derechos civiles, políticos y laborales en Cuba. A estas organizaciones EE.UU. le adjudicaría hasta \$ 11 millones en financiamientos que iban desde 500000 a 2 millones cada una.

EE.UU. declaró que se daría prioridad a aquellas propuestas que hicieran hincapié en el papel de los interlocutores cubanos en el desarrollo y logro de los objetivos antes mencionados. Las actividades a financiar abarcaban fundamentalmente becas de corta duración para capacitaciones. Estas actividades de capacitación se realizarían en diferentes países fuera de Cuba, incluyendo el propio EE.UU.

Estrategias como el Zunzuneo en los celulares, las becas World Learning, y la creación de perfiles falsos en Facebook, que simulan ser de estudiantes 
universitarios cubanos, cuyas publicaciones dan lugar a opiniones en contra del sistema político cubano, son algunos de los ejemplos que muestran el marcado interés por este sector poblacional. Influir en él y condicionar su estado de opinión con relación al gobierno cubano ha sido es la meta.

Naturalmente, la causa de esta política reside en que la juventud tiene gran influencia en la construcción y proyección de la imagen país, fundamentalmente en las redes sociales, pues estas les brindan la posibilidad de interactuar entre ellos y con el resto del mundo desde la cotidianidad de sus vidas.

La proyección de la imagen país construida por los jóvenes en las redes sociales es estratégica por considerarse este sector poblacional el presente y el futuro de la vida de la nación. De ahí, se derivan aspectos como la legitimidad que este sector poblacional otorga al sistema político del país, sus niveles de seguridad, el grado de satisfacción social, personal y profesional.
La atención directa al desarrollo integral de la juventud, a su educación, y la satisfacción de sus necesidades, tanto espirituales como materiales, en la medida en que la situación económica del país lo permite, así como el respeto y consideración de sus inquietudes, constituyen prioridades del sistema socialista cubano. Esa es la causa de que los jóvenes sean una fortaleza del país y representen un factor de cambio revolucionario. Por otro lado, se trata de un sector en formación, en proceso de maduración y, por ello, la generación de influencias e intentos de manipulación foráneas, constituyen herramientas que se perciben como eficaces y como peligros potenciales.

Es por ello que, como estrategia y principio del sistema, constituyen un foco del trabajo político y se introducen en sus planes de estudios, desde temprana edad, asignaturas que les permitan comprender la problemática nacional, el mundo que los rodea y los procesos políticos planetarios.

Una juventud fuerte que se sepa defender debe ser culta e instruida. Por 
ello entre las asignaturas que predominan en los currículos escolares y universitarios cubanos se pueden citar Historia de Cuba, Antigua y
Contemporánea, Filosofía, Marxismo, Cultura Política, Teoría Sociopolítica, Ciencia Política, entre otras.

\section{Conclusiones}

- Conocer Conocer el importante rol axiológico de la tecnología, su impacto directo en las sociedades modernas y en la internacionalización de los problemas, las culturas; así como el uso que de ella hacen los diversos países y actores sociales y políticos, es hoy en día un tema de suma importancia para todos, pues el mundo actual está compartido entre el ciberespacio y la realidad no conectada, ambas, aunque diferentes, son legítimas e integran la totalidad del escenario contemporáneo.

- $\quad$ El El trabajo con la imagen país integra los elementos del marketing, los posicionamientos del mercado y ha devenido en una importante herramienta para la política y las relaciones internacionales. Es por ello que existe una estrecha relación entre la construcción y proyección de la imagen país, Internet y las redes sociales. Facebook es una de las redes que goza de mayor popularidad a nivel internacional.

- El gobierno cubano, bajo la guía de su líder Fidel Castro, desde momentos tempranos, comprendió las amplias posibilidades que brindaba estar conectado a Internet, por lo que vio esta posibilidad como un derecho que todos los cubanos debían tener.

- $\quad$ El proceso de informatización de la sociedad cubana ha sido largo y complejo pues en él ha influido las políticas agresivas de EE.UU. con la aplicación del injusto bloqueo económico, comercial, financiero $y$ tecnológico impuesto hace casi 60 años

- Aunque son varios los ataques que la isla recibe a través del ciberespacio, la política que sigue el país es educar a los 
cubanos para que sean capaces de lidiar con los peligros que indudablemente, existen en Internet, pues, solo una población cibereducada es suficientemente sabía y fuerte para enfrentar estas agresiones en los momentos actuales.

\section{Índice}

Terrón, J. M. A. (2002): Los nuevos dispositivos tecnológicos de mediación de la experiencia y su repercusión en el relato reflejo del mundo social. Textos de la CiberSociedad, 2. Recuperado desde: http://www.cibersociedad.net. Consultado el 25 de octubre de 2020.

Carmenati, M. (2012): El espacio social en Habermas y Gramsci. Condiciones de posibilidad para la opinión pública. [Tesis de Doctorado, Facultad de Filosofía e Historia de La Universidad de La Habana], 50.

Chaguaceda, A. (2008): Participación ciudadana y espacio asociativo. La Habana: Ediciones Acuario, 37.

Colombo, C., Galais, C. \& Gallego, A. (2012) El uso de Internet y las actitudes políticas: datos cuantitativos y cualitativos de España. Arbor, 756, 751-766.

De Rivera, J. (2011): El sujeto colectivo y la segunda sociología de las redes sociales. Sociología y Redes sociales. Recuperado desde: 
http://www.sociologiayredessociales.com/2011/06/el-sujeto-colectivo-y-lasegunda-sociologiade-las-redes-sociales /. Consultado el 15 de agosto de 2018,10 .

Díaz, E. \& Sokooh, F. (2013): Internet y las TIC en Cuba: notas para un debate sobre políticas públicas. Temas, 74, 62-67.

Gómez, S. J. (2020): Guerra Mediática: de la racionalidad a la motividad. Recuperado desde:

https://www.cubainformacion.tv/opinion/20200730/87282/87282-guerramediatica-de-la-racionalidad-a-la-emotividad Consultado el 30 de julio de 2020.

Marrero, L. (2013). Cuando los mapas se convierten en redes. [Tesis de Maestría, Facultad de Comunicación de La Universidad de La Habana], 67.

Orozco, G. (1991): La audiencia frente a la pantalla. Diálogos de la comunicación. Diálogos de la comunicación No.30, 54-63.

Armando, C. N. (2008). Participación y espacio asociativo. En Raventós, C. Innovación democrática en el sur: participación y representación en Asia, África y América Latina. Buenos Aires: Consejo Latinoamericano de Ciencias Sociales, 59-82. 
Maya, R. P. (2013) Libertad de información e independencia judicial, en Maya, R.P. Discriminación, principio de jurisdicción universal y temas de derecho penal. Bogotá: Uniandes, 682- 7683.

Rodríguez, A. (2012): Artesanías de sentidos. [Tesis de Maestría, Facultad de Comunicación de La Universidad de La Habana], 15-45.

Sánchez, I. (2020) Estado, pueblo y medios de comunicación: ¿nos entregamos?

https://lapupilainsomne.wordpress.com/2020/08/24/lapupilacumple10estado-pueblo-y-medios-de-comunicacion-nos-entregamos-por-iroelsanchez/ Consultado el 24 de agosto de 2020.

Sued, G. (2010). Pensando a Facebook, una aproximación colectiva por dimensiones. En Piscitelli, A. et al. (2010). El proyecto Facebook y la posuniversidad. Sistemas operativos sociales y entornos abiertos de aprendizaje. Argentina: Colección Fundación Telefónica, 59-70.

Tello, L. (2013). Intimidad y «extimidad» en las redes sociales. Las demarcaciones éticas de Facebook. Comunicar, 41.

Recebido em: 15/08/2020

Aprovado em: 10/12/2020 